\title{
Ischemic stroke causes Parkinson's disease-like pathology and symptoms in transgenic mice overexpressing alpha-synuclein
}

Stephanie Lohmann ${ }^{1}$, Jessica Grigoletto ${ }^{1}$, Maria Eugenia Bernis ${ }^{1}$, Verena Pesch², Liang Ma², Sara Reithofer ${ }^{2}$ and Gültekin Tamgüney ${ }^{2,3^{*}}$ (1)

\begin{abstract}
The etiology of Parkinson's disease is poorly understood and is most commonly associated with advancing age, genetic predisposition, or environmental toxins. Epidemiological findings suggest that patients have a higher risk of developing Parkinson's disease after ischemic stroke, but this potential causality lacks mechanistic evidence. We investigated the long-term effects of ischemic stroke on pathogenesis in hemizygous TgM83 mice, which express human a-synuclein with the familial A53T mutation without developing any neuropathology or signs of neurologic disease for more than 600 days. We induced transient focal ischemia by middle cerebral artery occlusion in 2-monthold TgM83 ${ }^{+/-}$mice and monitored their behavior and health status for up to 360 days post surgery. Groups of mice were sacrificed at 14,30,90,180, and 360 days after surgery for neuropathological analysis of their brains. Motor deficits first appeared 6 months after focal ischemia and worsened until 12 months afterward. Immunohistochemical analysis revealed ischemia-induced neuronal loss in the infarct region and astrogliosis and microgliosis indicative of an inflammatory response, which was most pronounced at 14 days post surgery. Infarct volume and inflammation gradually decreased in size and severity until 180 days post surgery. Surprisingly, neuronal loss and inflammation were increased again by 360 days post surgery. These changes were accompanied by a continuous increase in a-synuclein aggregation, its neuronal deposition, and a late loss of dopaminergic neurons in the substantia nigra, which we detected at 360 days post surgery. Control animals that underwent sham surgery without middle cerebral artery occlusion showed no signs of disease or neuropathology. Our results establish a mechanistic link between ischemic stroke and Parkinson's disease and provide an animal model for studying possible interventions.
\end{abstract}

Keywords: Ischemic stroke, Ischemia, Stroke, Parkinson's disease, Synucleinopathy, Alpha-synuclein

\footnotetext{
${ }^{*}$ Correspondence: erdem@fz-juelich.de

${ }^{2}$ Institut für Biologische Informationsprozesse, Strukturbiochemie (IBI-7),

Forschungszentrum Jülich GmbH, Wilhelm-Johnen-Straße, 52425 Jülich, Germany

Full list of author information is available at the end of the article
}

\section{Introduction}

Stroke is the third most common cause of death after ischemic heart disease and neonatal disorders, causing $9 \%$ of all fatalities worldwide, and even silent strokes without any immediate clinical manifestation are observed in up to $28 \%$ of the population [14, 54]. Approximately $87 \%$ of all stroke cases are ischemic, and are associated with a risk that increases with age, as $18 \%$ of individuals over 45 years of age have already experienced original author(s) and the source, provide a link to the Creative Commons licence, and indicate if changes were made. The images or other third party material in this article are included in the article's Creative Commons licence, unless indicated otherwise in a credit line to the material. If material is not included in the article's Creative Commons licence and your intended use is not permitted by statutory regulation or exceeds the permitted use, you will need to obtain permission directly from the copyright holder. To view a copy of this licence, visit http://creativecommons.org/licenses/by/4.0/. The Creative Commons Public Domain Dedication waiver (http://creativeco mmons.org/publicdomain/zero/1.0/) applies to the data made available in this article, unless otherwise stated in a credit line to the data. 
symptoms of stroke [20,56]. Ischemic stroke leads to oxygen deprivation in the affected brain tissue with a subsequent loss of physiological cell functions and often permanent tissue damage within seconds $[15,41]$. On a molecular basis, ischemia induces a cascade of deleterious events in the ischemic core, including an imbalance of membrane homeostasis due to $\mathrm{Ca}^{2+}$-influx, glutamate and cytochrome $\mathrm{c}$ release, oxidative and endoplasmic reticulum stress, mitochondrial dysfunction, activation of caspases, and inflammatory responses [15, 41]. Ultimately, ischemic stroke results in neuronal death by enhanced autophagy, apoptosis, and necrosis [15, 41]. Reoxygenation of ischemic tissue during reperfusion further enhances the detrimental primary effects of ischemia by an increase of neurotoxic reactive oxygen and nitrogen species $[13,21]$. This secondary neuronal injury upon reperfusion also triggers inflammatory and pathological changes in brain regions connected to the ischemic core $[8,59]$. Next to these short-term effects, ischemic stroke has many long-term consequences [56]. Stroke and silent strokes are associated with a higher risk of progression to dementia and cognitive decline $[1,30,55]$. Epidemiological studies have also revealed an increased risk of Parkinson's disease (PD) after ischemic stroke, but there is currently no mechanistic model that adequately explains this association $[6,28]$.

$\mathrm{PD}$ is a neurodegenerative disorder characterized by pathologic depositions of $\alpha$-synuclein in neurons that are referred to as Lewy bodies and Lewy neurites $[4,23$, 49]. Pathologic $\alpha$-synuclein is neurotoxic and causes the loss of dopaminergic neurons in the substantia nigra, which eventually results in motor symptoms due to an insufficient supply of the striatum with dopamine [23]. $\alpha$-Synuclein is a 140 amino acid long and, under physiological conditions, mostly unstructured and soluble protein, which has regulatory functions in synaptic vesicle recycling in presynaptic terminals [11]. Unfavorable cellular conditions can induce $\alpha$-synuclein to adopt pathologic conformations and assemble into oligomers and fibrils [42, 46-48]. These pathologic aggregates of $\alpha$-synuclein have the capacity to recruit and template misfolding of naïve $\alpha$-synuclein, and to propagate within the nervous system in a prion-like manner [7, 9, 27, 31, 34, 52]. While genetic risk factors, including mutations affecting the SNCA gene encoding $\alpha$-synuclein, explain approximately $16-36 \%$ of the heritable risk of $\mathrm{PD}$, the etiology of idiopathic PD is not well understood with advancing age being the biggest risk factor $[3,23,38]$.

Here we investigated the role of mild ischemic stroke in the pathogenesis of PD in TgM83 $3^{+/-}$mice overexpressing human $\alpha$-synuclein with the familial A53T mutation [19]. These mice do not naturally develop neuropathology or signs of neurologic disease for more than 600 days unless they are challenged with $\alpha$-synuclein fibrils [10, 32 , 57]. We induced transient focal cerebral ischemia in young $\mathrm{TgM} 83^{+/-}$mice by middle cerebral artery occlusion (MCAO) and investigated the effects of ischemia for up to a year post ischemia. Sham-treated mice remained healthy throughout the entire duration of the experiment and exhibited no neuropathological changes. In contrast, MCAO induced a synucleinopathy in $\mathrm{TgM} 83^{+/-}$mice as defined by cerebral $\alpha$-synuclein aggregation and deposition, neuroinflammation, loss of dopaminergic neurons in the substantia nigra, and motor deficits. Our results show that ischemia can trigger sustained $\alpha$-synuclein aggregation, providing a mechanistic link that explains how ischemic stroke increases the risk for PD.

\section{Materials and methods}

\section{Mouse husbandry}

Mice were housed under standard conditions with a $12 \mathrm{~h}$ light/dark cycle with free access to food and water. B6;C3$\mathrm{Tg}$ (Prnp-SNCA*A53T)83Vle/J mice (short: TgM83 mice, The Jackson Laboratory) overexpressing the A53T mutant of human $\alpha$-synuclein under the prion promoter on a C57BL/6 background [9] were crossed to wild-type C57BL/6 J mice and their progeny were genotyped for the presence of the transgene.

\section{Middle cerebral artery occlusion}

Six- to eight-week-old male and female $\mathrm{TgM} 83^{+/-}$mice were subjected to either focal cerebral ischemia by middle cerebral artery occlusion (MCAO, $n=10$ /group) or a sham control surgery (sham, $\mathrm{n}=6 /$ group). TgM $83^{+/-}$ mice were anaesthetized with isoflurane and treated with carprofen as an analgesic, after which surgery was carried out on a heating pad to prevent hypothermia. A midline incision was made and the right common carotid artery (CCA) was carefully separated from surrounding tissue and the vagus nerve. A permanent ligation was made $4 \mathrm{~mm}$ proximal to the bifurcation, which splits the CCA into the external carotid artery (ECA) and the internal carotid artery (ICA) using 6/0 sutures (Feuerstein). The CCA was clipped proximal to the bifurcation and the ECA was also clipped with a vascular clamp to prevent backflow from the distal vasculature. A microincision into the CCA, distal to the permanent knot, was made with spring scissors to insert a silicon-coated filament (Doccol) into the right CAA. Following insertion, the clip at the bifurcation was removed and the filament gently guided 9 to $11 \mathrm{~mm}$ into the ICA until the filament tip occluded the middle cerebral artery (MCA). The filament was fixed in this position for $30 \mathrm{~min}$ with an additional suture directly distal to the microincision. After $30 \mathrm{~min}$ of MCAO, the suture was shortly opened to remove the filament and then directly closed with a permanent 
ligation to allow natural reperfusion. The vascular clamp was removed and the neck incision was sutured with $4 / 0$ black silk (Himed). The mice were then transferred to a heated cage and constantly monitored until full recovery from surgery. Sham control mice underwent the same surgical procedure of ligation and microincision of the CCA except for insertion of a filament. Treated animals were monitored daily for health and three times weekly for signs of neurological disease, such as reduced grooming, ataxia, bradykinesia, lethargy, paraparesis, paralysis, and kyphosis. Mice were sacrificed at 14, 30, 90, 180, and 360 days post surgery and their brains analyzed.

\section{Behavioral analysis}

Motor function and coordination were evaluated with a rotarod test at 90,180 , and 360 days post surgery. Mice were placed on a horizontal and accelerating (4 to $40 \mathrm{rpm}$ ) rotarod treadmill (Ugo Basile) for a maximum of $300 \mathrm{~s}$. Each animal was tested four times with a 5 min rest period between each trial on a particular test day, and the mean value of the last three trials was taken as an animal's performance on that day.

\section{Immunohistochemical analysis}

For immunohistochemical analysis, mice were overdosed with ketamine/xylazine and transcardially perfused with $0.9 \%(\mathrm{w} / \mathrm{v})$ saline followed by $10 \%(\mathrm{v} / \mathrm{v})$ formalin neutral buffer solution (Sigma). After removal, brains were fixed overnight in $10 \%$ formalin neutral buffer solution. Formalin-fixed brains were dehydrated in a series of graded ethanol and xylene baths, and embedded in paraffin. Brains were cut into $6-\mu \mathrm{m}$-thick coronal sections using a RM2255 microtome (Leica), mounted on glass slides, dried overnight, and stored at $4{ }^{\circ} \mathrm{C}$. Brain sections were first deparaffinized in xylene, and then rehydrated in a series of graded ethanol baths. For antigen-retrieval either 1-min incubation in $88 \%$ formic acid or heatinduced antigen-retrieval with citric buffer ( $\mathrm{pH}$ 6.0) was used. Endogenous peroxidase activity in the tissue was inhibited by incubation with $5 \%(\mathrm{v} / \mathrm{v})$ hydrogen peroxide solution for $30 \mathrm{~min}$. Brain sections were blocked with $20 \%(\mathrm{v} / \mathrm{v})$ normal goat serum and $1 \%(\mathrm{v} / \mathrm{v})$ bovine serum albumin (BSA) in $0.5 \%(\mathrm{v} / \mathrm{v})$ Triton X-100 in PBS for $1 \mathrm{~h}$ at room temperature. The primary antibody was diluted in $1 \%(\mathrm{v} / \mathrm{v})$ normal goat serum, $1 \%(\mathrm{v} / \mathrm{v}) \mathrm{BSA}$, and $0.25 \%$ (v/v) Triton X-100 in PBS and incubated overnight at room temperature. Antibodies used in this study with corresponding dilutions and antigen-retrievals are listed in Additional file 1. After washing once with $0.25 \%(\mathrm{v} / \mathrm{v})$ Triton X-100 in PBS and twice with PBS, tissue sections were incubated for $1 \mathrm{~h}$ with peroxidase-conjugated secondary antibody using the Mouse on Mouse or Vectastain $\mathrm{ABC}$ kit (Vector Lab) diluted in 1\% (v/v) normal goat serum and $1 \%(\mathrm{v} / \mathrm{v})$ BSA in PBS at room temperature. The last step was omitted for phospho- $\alpha$-synucleinstaining with the biotinylated pSyn\#64 antibody (Wako). After washing once with $0.25 \%(\mathrm{v} / \mathrm{v})$ Triton X-100 in PBS and twice with PBS, peroxidase-positive structures were visualized by incubation with DAB (3-3'-diaminobenzidine, Vector Labs). The oxidation process was stopped with $3 \%(\mathrm{v} / \mathrm{v})$ hydrogen peroxide solution. Tissue sections were counterstained with Mayer's hematoxylin (Merck), coverslipped with Eukitt (Sigma), scanned with a slide scanner (AxioScan.Z1, Carl Zeiss) or with an Epi-Scope1Apotome (Carl Zeiss), and analyzed using Fiji software.

\section{Immunofluorescence analysis}

Paraffin-embedded tissues were cut into 6 - $\mu \mathrm{m}$-thick coronal sections, mounted on glass slides, deparaffinized, and rehydrated as indicated before. For antigen retrieval, slides were incubated in citrate buffer ( $\mathrm{pH}$ 6.0). After cooling down and washing twice with PBS, autofluorescence of the tissue was quenched by incubation in $\mathrm{CuSO}_{4}$ for $120 \mathrm{~min}$ at room temperature [45]. The slides were blocked in $20 \%(\mathrm{v} / \mathrm{v})$ normal goat serum, $1 \%(\mathrm{v} / \mathrm{v})$ BSA, and $0.5 \%(\mathrm{v} / \mathrm{v})$ Triton X-100 in PBS for $1 \mathrm{~h}$ at room temperature. Sections were then incubated with a primary antibody in $1 \%(\mathrm{v} / \mathrm{v})$ normal goat serum, $1 \%(\mathrm{v} / \mathrm{v})$ BSA, and $0.25 \%$ Triton X-100 in PBS overnight at room temperature. Antibodies used in this study with the corresponding dilutions are listed in Additional file 1. After washing once with $0.25 \%(\mathrm{v} / \mathrm{v})$ Triton X-100 in PBS, and twice with PBS, sections were stained with corresponding Alexa Fluor 488-, Alexa Fluor 594-, or Alexa Fluor 647-conjugated (Thermo Fisher Scientific) secondary antibodies and the nuclear dye DAPI (4',6-diamidino2-phenylindole; Thermo Fisher Scientific) in 1\% (v/v) normal goat serum, $1 \%(\mathrm{v} / \mathrm{v}) \mathrm{BSA}$, and PBS for $1 \mathrm{~h}$ at room temperature. Slides were washed three times, coverslipped with Fluoromount medium (Sigma) and visualized with an LSM700 confocal laser-scanning microscope (Carl Zeiss).

\section{Preparation of mouse brain homogenates for biochemical analyses}

For biochemical analyses brains were separated into ipsiand contralateral hemispheres, snap-frozen on dry ice, and stored at $-80^{\circ} \mathrm{C}$. Brain samples were homogenized in icecold $\mathrm{Ca}^{2+}$ - and $\mathrm{Mg}^{2+}$-free PBS (pH 7.4) in the presence of phosphatase and protease inhibitors (HALT inhibitor cocktail; Thermo Fisher Scientific) by two 30-s cycles at $6500 \mathrm{rpm}$ in a Precellys 24-Dual homogenizer (Peqlab) to reach a final concentration of $10 \%(\mathrm{w} / \mathrm{v})$. Total protein concentration was determined using the Pierce BCA Protein Assay Kit (Thermo Fischer Scientific). 


\section{Quantification of oligomerized and aggregated a-synuclein by fluorescence resonance energy transfer (FRET)}

Oligomers and aggregates of human $\alpha$-synuclein in brain homogenates were quantified by fluorescence resonance energy transfer (FRET) using a commercially available kit (6FASYPEG, Cisbio). Briefly, triplicates of $10-\mu \mathrm{L}$ samples with $1 \mu \mathrm{g}$ total protein were prepared from $10 \%(\mathrm{w} / \mathrm{v})$ ipsi- and contralateral brain homogenate in $1 \times$ lysis buffer. Ten microliter of a pre-mixed antibody solution containing anti-h- $\alpha$-Synuclein-d2 (acceptor) and anti$\mathrm{h}-\alpha$-Synuclein-Tb-Cryptase (donor) were added to each sample. A negative control, Cryptase control and buffer control were prepared as suggested by the company. Twenty microliter of the final mix containing sample and antibody as well as the controls were transferred on a 384-well flat clear-bottom plate (Greiner Bio-One), covered with a plate sealer, and incubated for $20 \mathrm{~h}$ at room temperature. Fluorescence emission was measured at $665 \mathrm{~nm}$ for FRET-dependent acceptor fluorescence and at $620 \mathrm{~nm}$ for FRET-independent donor fluorescence on a CLARIOstar microplate reader (BMG Labtech). The ratio of both fluorescence emission values multiplied by 10,000 is directly proportional to the amount of human $\alpha$-synuclein oligomers and aggregates in each sample.

\section{Quantification of total human a-synuclein by immunoassay}

The concentration of total human $\alpha$-synuclein in brain homogenates was quantified by a colorimetric horseradish peroxidase-linked immunoassay using a commercially available anti- $\alpha$-synuclein ELISA kit (AS-55550-H, AnaSpec). Briefly, $10 \%$ ipsi- and contralateral brain homogenate was diluted 1:100,000 in dilution buffer, transferred on a 96-well strip plate in triplicates, and co-incubated with $1 \mu \mathrm{g} / \mathrm{mL}$ of the detection antibody at $4{ }^{\circ} \mathrm{C}$ overnight. After washing the plate six times, TMB substrate solution $\left(3,3^{\prime}, 5,5^{\prime}\right.$-tetramethylbenzidine) was added. The color reaction was stopped after an incubation period of $5 \mathrm{~min}$ at $37{ }^{\circ} \mathrm{C}$ by adding stop solution, and absorbance was measured at $450 \mathrm{~nm}$ on a FLUOstar microplate reader (BMG Labtech).

\section{Quantification of the infarct volume in histological sections} The infarct volume of each brain was measured under masked conditions. Areas of NeuN-positive staining were measured using Fiji in the ipsi- and contralateral hemispheres of three MCAO-treated animals for each time point and of eight sham-treated animals. To minimize potential error caused by edema, the infarct volume was calculated in relation to the contralateral hemisphere according to Swanson et al. (contralateral hemisphere minus ipsilateral non-infarct area divided by contralateral hemisphere) [51]. The total infarct volume was measured in coronal sections ranging from bregma $0.14 \mathrm{~mm}$ to $-1.22 \mathrm{~mm}$ and presented as mean percentage of the contralateral hemisphere \pm standard error (SEM).

\section{Quantification of neuroinflammation in histological sections}

Gliosis within the penumbra region was quantified in coronal sections ranging from bregma $0.26 \mathrm{~mm}$ to $-1.70 \mathrm{~mm}$ in three sham-treated and five MCAOtreated animals per group and time point. Quantification was performed under masked conditions. Ionized calcium-binding adapter molecule 1 (Iba1)-positive staining was quantified in two separate tissue sections with six separate one square-millimeter-sized areas for each ipsi- and contralateral side. Glial fibrillary acidic protein (GFAP)-positive staining was quantified in two separate tissue sections with three separate one square-millimeter-sized areas for each ipsi- and contralateral side. Digitalized images were converted to an 8-bit format and the lower and upper thresholds were set to 0 and 130, respectively. The lower and upper thresholds represent mean values of manually analyzed images for MCAOand sham-treated animals. The area of Iba1- or GFAPpositive staining was measured in each image using a Fiji macro. Data are presented as mean percentages \pm standard deviation (SD).

\section{Quantification of dopaminergic neurons in histological sections}

Quantification of dopaminergic neurons was based on a previously described method [26]. Dopaminergic neurons characterized by visible nuclei after hematoxylin staining and by entire neuronal somas positive for tyrosine hydroxylase were quantified under masked conditions in three sham-treated and five MCAO-treated animals per time point. The number of tyrosine hydroxylasepositive cells was counted in both brain hemispheres in matching sets of coronal midbrain sections at $-2.90 \mathrm{~mm}$, $-3.08 \mathrm{~mm},-3.26 \mathrm{~mm}$, and $-3.44 \mathrm{~mm}$ relative to bregma, and the area of the substantia nigra was identified corresponding to areas depicted in figures 55 to 60 of a mouse brain atlas [16]. The data was summarized for each group and hemisphere as mean tyrosine hydroxylase-positive cells \pm standard deviation (SD) per section.

\section{Quantification of phosphorylated a-synuclein in histological sections}

For quantification of brain areas with staining for phosphorylated $\alpha$-synuclein, coronal sections at bregma 0.7 $4 \mathrm{~mm},-1.70 \mathrm{~mm},-2.92 \mathrm{~mm},-4.84 \mathrm{~mm}$, and $-5.68 \mathrm{~mm}$ 
were used. Digitalized images were masked prior to analysis. Cells positive for phosphorylated $\alpha$-synuclein were counted in each region in both brain hemispheres of four animals at 360 days after stroke, and averages of phosphorylated $\alpha$-synuclein-positive cells per square millimeter per region were presented in a color-coded heat map.

\section{Statistical analysis}

Statistical tests were carried out using Prism 8.0 (GraphPad). To assess differences among multiple groups two-way analysis of variance (ANOVA) with multiple comparisons was used, based on the row factor time point and the repeated measures in each column factor of ipsi-/ contralateral stroke or sham surgery. Due to the multiple comparisons of the row and column means, we corrected using Tukey's post-hoc test. As the calculation of the infarct volume already included ipsi- and contralateral hemispheres to reduce the effect of the edema, one-way ANOVA was used to assess differences within the sham group and stroke group at the different time points. Data are presented as mean \pm standard deviation (SD), unless stated otherwise. $P$ values below 0.05 were considered statistically significant.

\section{Results}

$\mathrm{TgM} 3^{+/-}$mice subjected to MCAO continuously gain body weight but develop motor deficits within 180 days after surgery that further worsen over time

We induced a mild, 30-min-long focal ischemia in the right brain hemisphere of 6-8-week-old male and female $\mathrm{TgM}_{8} 3^{+/-}$mice by middle cerebral artery occlusion (MCAO). Control mice underwent sham surgery without occlusion of their right middle cerebral artery. All animals subjected to surgery quickly recovered within an hour without showing any lasting signs of disability or disease. Because we were only interested in the longterm effects of stroke, motor deficits were not tested until 90 days after stroke. Mild motor deficits that might have been present at earlier time points during the acute reperfusion phase were not examined. Groups of 10 treated animals were sacrificed 14, 30, 90, 180, and 360 days post surgery for histological and biochemical analyses of both brain hemispheres (Fig. 1a). At these predefined endpoints, none of the animals displayed any overt signs of neurological illness, such as kyphosis, ataxia, or loss in body weight, which $\mathrm{TgM} 83^{+/-}$mice develop given enough time after challenge with preformed fibrils of

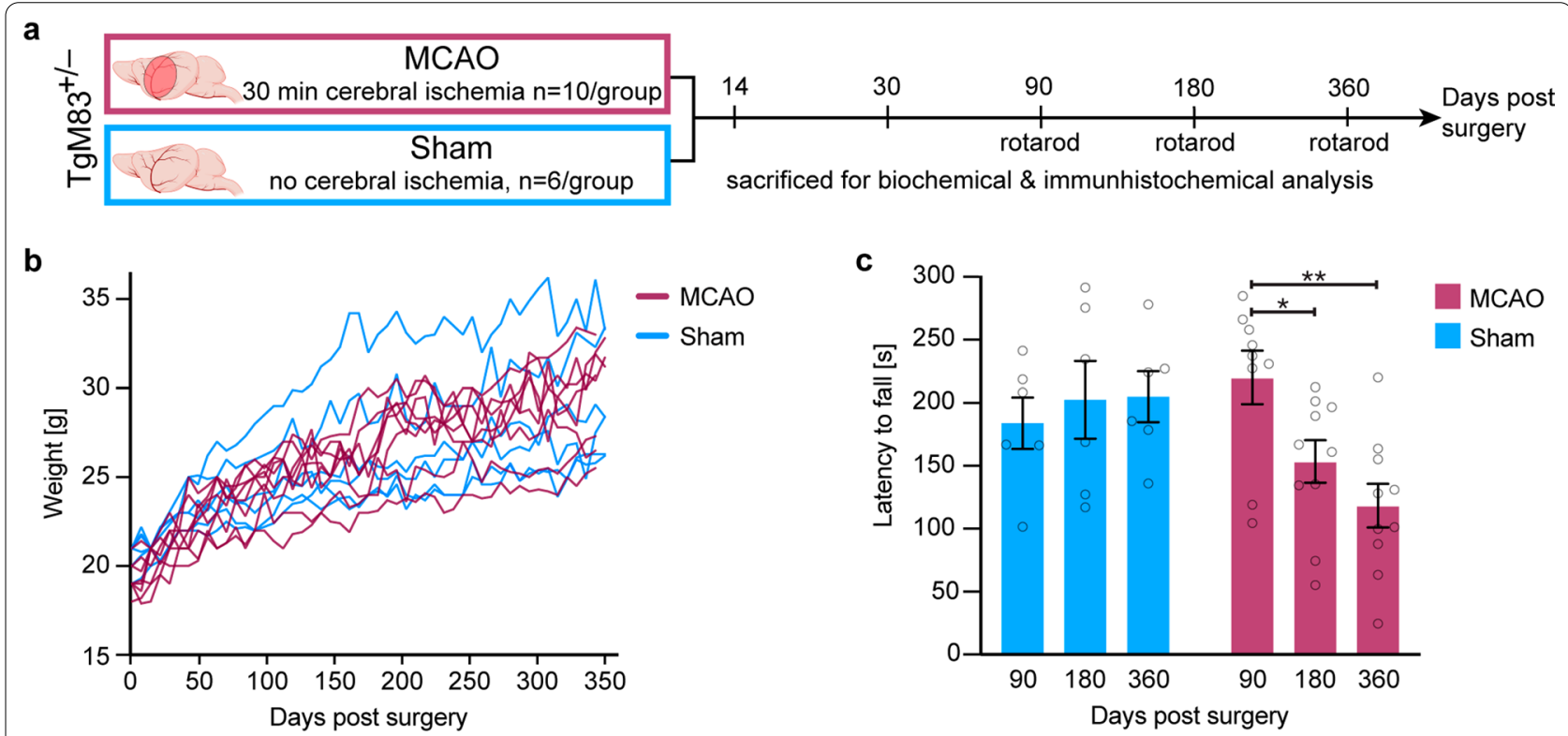

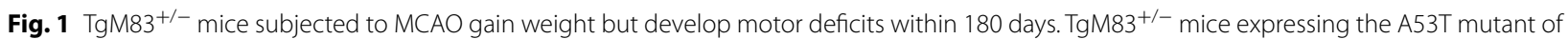
human a-synuclein were subjected to middle cerebral artery occlusion (MCAO) for 30 min or sham surgery without occlusion of the artery. Groups of treated animals were sacrificed at 14,30,90,180, and 360 days post surgery and neuropathology was analyzed by histology and biochemistry (a). Additionally, the motor behavior of treated animals was tested at 90,180 , and 360 days post surgery on a rotarod treadmill (a). TgM83 ${ }^{+/-}$mice subjected to MCAO ( $n=8$, red lines) as well as sham-treated animals ( $n=6$, blue lines) gained body weight until the end of the experiment at 360 days post surgery (b). MCAO- and sham-treated mice were tested for motor impairment using a rotarod at 90, 180, and 360 days post surgery. $\mathrm{TgM} 3^{+/-}$mice that had been subjected to MCAO (red) showed significantly reduced motor skills at 180 and 360 days post surgery relative to 90 days post surgery (c). In contrast, sham-treated control animals (blue) did not develop any motor deficits. Six to ten animals were analyzed per group. The data represents the mean latency to fall in seconds \pm standard error of the mean. $P$ values were computed using two-way ANOVA followed by Tukey's post-hoc test $\left(P:{ }^{*}<0.05,{ }^{* *}<0.01\right)$ 
$\alpha$-synuclein or brain homogenates of patients with multiple system atrophy containing $\alpha$-synuclein aggregates $[10$, $32,57]$. In addition, $\mathrm{TgM} 83^{+-}$mice subjected to $\mathrm{MCAO}$ as well as the control animals, which underwent surgery, had an overall gain in body weight until the end of the experiment at 360 days post surgery (Fig. 1b). Obvious differences between MCAO- and sham-treated animals only became detectable when tested for motor impairment using a rotarod treadmill 90, 180, and 360 days post surgery (Fig. 1c). In contrast to sham-treated control animals, which did not develop any motor deficits, $\mathrm{TgM}_{83} 3^{+/-}$mice that had undergone MCAO showed a significant $30 \%$ reduction in their motor skills 180 days post surgery that further dropped to $46 \%$ at 360 days post surgery compared to their performance at 90 days post surgery.

\section{$\mathrm{TgM}^{+/-}$mice display an early and a recurring late neuronal loss after stroke}

To quantify the lesion volume in the brains of $\operatorname{TgM} 83^{+/-}$ mice after $\mathrm{MCAO}$, we prepared brain tissue sections and stained neurons by immunohistochemistry with the MAB377 antibody for NeuN (Fig. 2a). The brains of all stroke animals exhibited typical subcortical damage in the striatum (Fig. 2a), whereas brains of control animals did not show any structural changes (Additional file 2). At fourteen days after MCAO we measured an average infarct volume of $15.8 \%$ in the ipsilateral brain hemisphere relative to the healthy contralateral brain hemisphere of $\mathrm{TgM} 83^{+/-}$mice (Fig. 2b). By 180 days post surgery the original infarct volume had gradually decreased to $2.8 \%$ (Fig. 2b). Reductions in the lesion volume after mild cases of cerebral ischemia over extended periods of time have been reported previously [24, 43]. Surprisingly, by 360 days after MCAO the lesion volume had increased to $12.0 \%$ again, indicative of a renewed neurodegenerative process in the original lesion area beginning sometime between 180 and 360 days after surgery. In contrast, brain tissue sections of $\mathrm{TgM} 83^{+/-}$mice that had only undergone sham surgery revealed very little to no neuronal loss over the entire 360-day period after surgery (Fig. 2b, Additional file 2).

\section{$\mathrm{TgM}^{+/-}$mice display a biphasic inflammatory process in the brain after stroke}

To assess neuroinflammatory changes in the brains of $\mathrm{TgM} 3^{+/-}$mice after MCAO and sham surgery, we prepared coronal brain tissue sections of animals sacrificed at $14,30,90,180$, and 360 days post surgery and stained astrocytes with an antibody to GFAP and microglia with an antibody to Iba-1 (Fig. 3a). Quantification of the GFAP- and Iba-1-staining in and around the lesion area revealed that following MCAO microgliosis (Fig. 3b) and astrogliosis (Fig. 3c) were significantly induced in the brains of mice subjected to MCAO at 14 days post surgery when compared to the contralateral hemisphere.
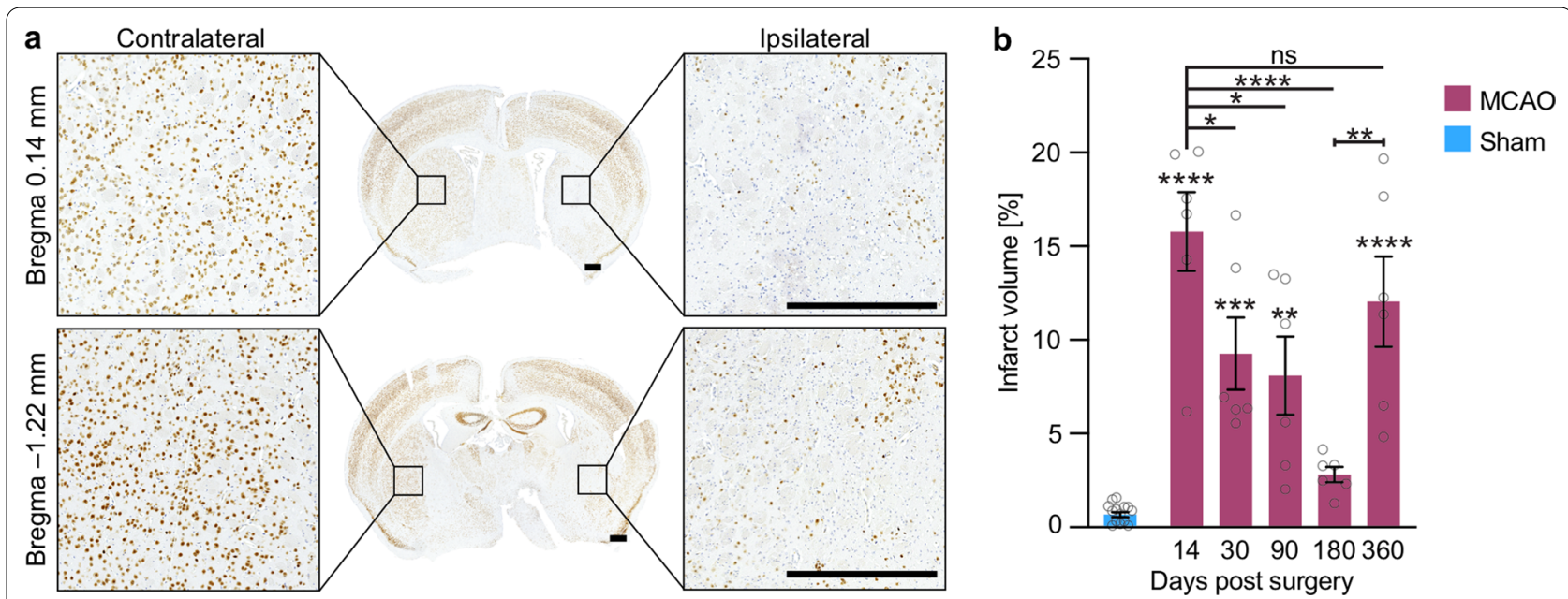

Fig. $2 \mathrm{TgM}^{+/-}$mice show neuronal loss in the ipsilateral brain hemisphere after MCAO. Immunohistochemical staining for the neuronal marker NeuN showed an ipsilateral loss of neurons in ischemic brains of TgM83 ${ }^{+/-}$mice after MCAO (a). Quantification of brain tissue sections ranging from bregma $0.14 \mathrm{~mm}$ to $-1.22 \mathrm{~mm}$ of mice subjected to MCAO revealed significant ipsilateral neuronal degeneration in the ischemic core and peri-infarct region at 14,30,90,180, and 360 days post surgery relative to sham-treated animals (b). The infarct size was calculated in relation to the contralateral brain hemisphere to minimize the error caused by edema. Two coronal brain sections of three MCAO-treated animals were analyzed for each time point and two coronal brain sections of eight sham-treated animals for all time points together. The data represents the mean infarct volume in percent \pm standard error of the mean. $P$ values were computed using one-way ANOVA followed by Tukey's post-hoc test $\left(P\right.$ : ${ }^{* * *}<0.0001$, $\left.{ }^{* *}<0.001,{ }^{* *}<0.01\right)$. The scale bar represents $0.5 \mathrm{~mm}$ 


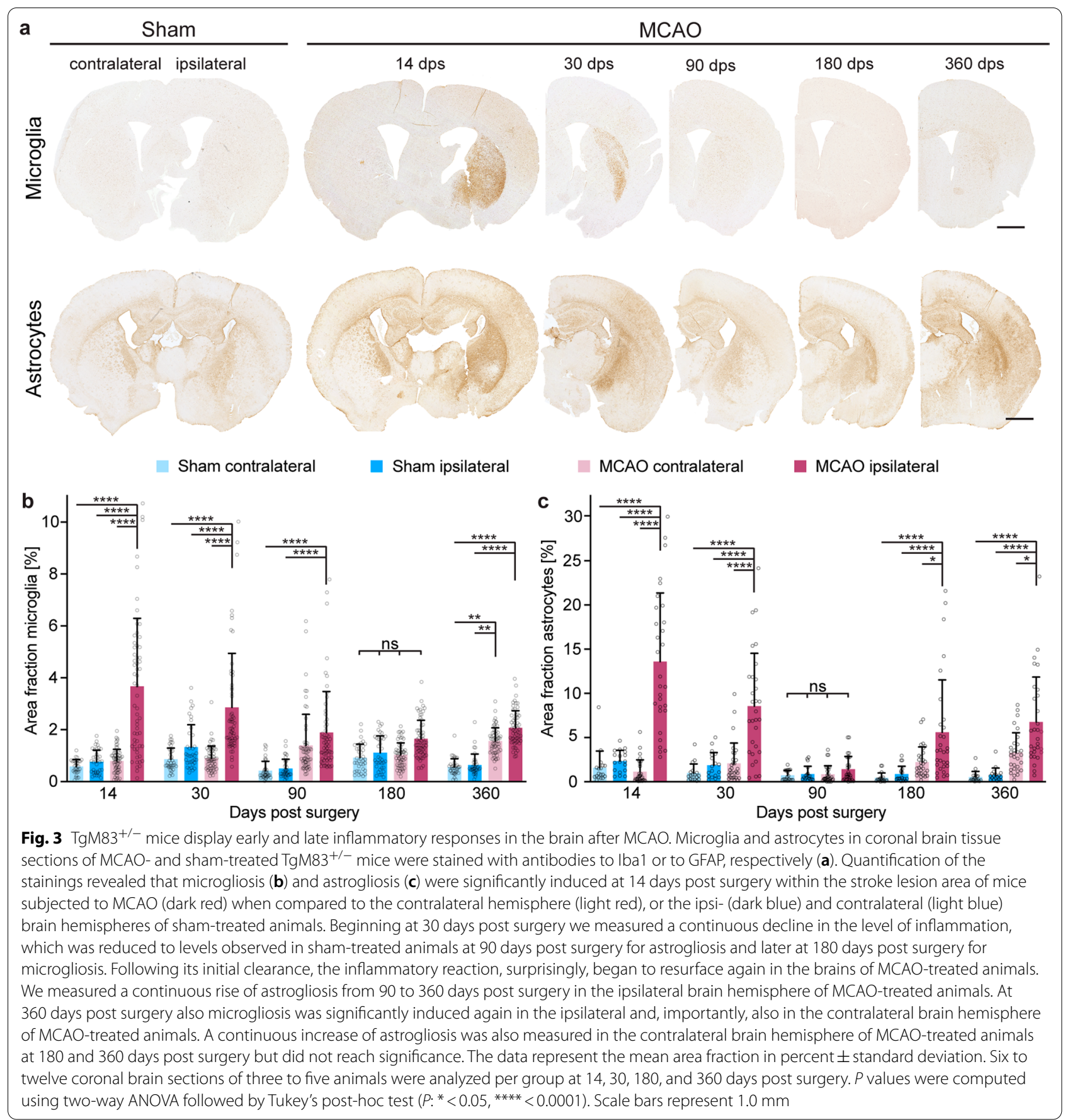

The primary inflammatory reaction gradually subsided and astrogliosis had fully receded by 90 days and microgliosis by 180 days post surgery. In response to the secondary neurodegenerative process that we detected in the lesion area in the brains of mice between 180 and 360 after MCAO, astrogliosis was induced again sometime between 90 and 180 days post surgery followed by microgliosis after 180 days post surgery. Also, by 360 days post surgery, inflammation had spread from the ipsilateral to the contralateral brain hemisphere of MCAOtreated mice, as seen by significantly elevated levels of microgliosis in both brain hemispheres in comparison to sham-treated animals (Fig. 3, Additional file 3). A similar gradual increase of astrogliosis was also seen in the contralateral brain hemisphere of MCAO-treated 
animals at 180 and 360 days post surgery without reaching significance.

\section{$\mathrm{TgM}^{+/-}$mice display a late loss of dopaminergic neurons in the substantia nigra after stroke}

To investigate whether the motor deficits, which $\mathrm{TgM}_{83}{ }^{+/-}$mice displayed beginning at 180 days after stroke, may have been caused by a loss of dopaminergic neurons in the substantia nigra, we stained midbrain tissue sections of animals sacrificed at 14, 30, 90, 180, and 360 days post surgery with an antibody to tyrosine hydroxylase (TH) (Fig. 4a). Quantification of tyrosine hydroxylase-positive neurons of the substantia nigra

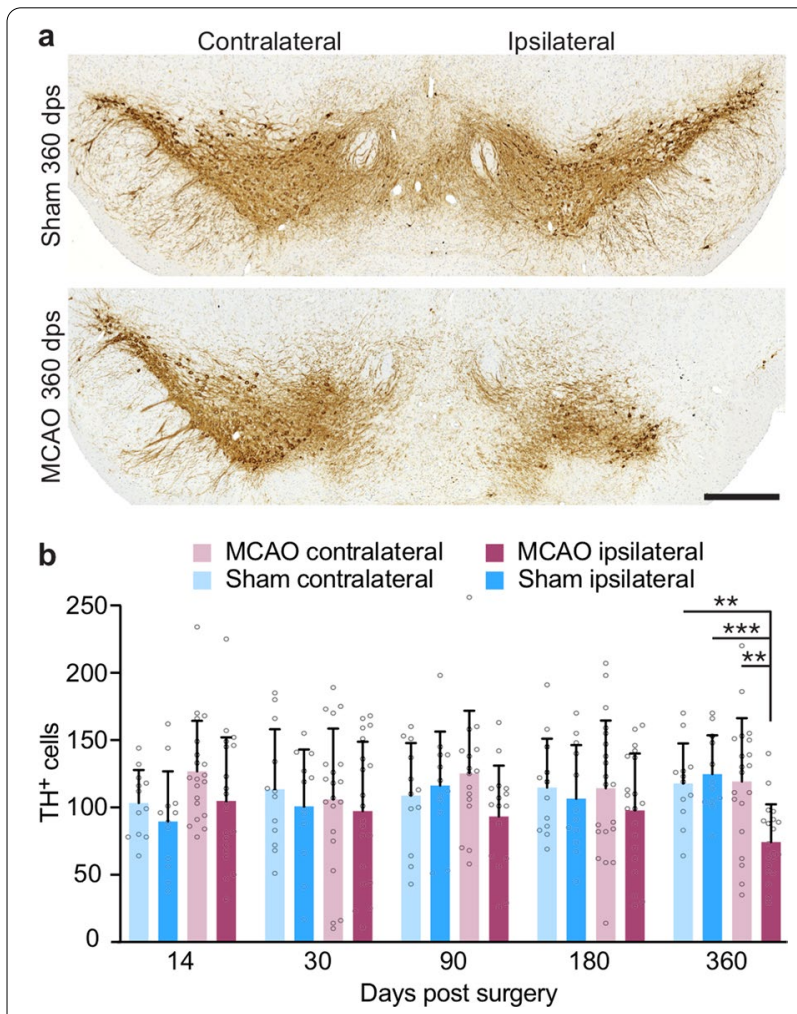

Fig. 4 MCAO-treated TgM83 ${ }^{+/}$- mice display a late loss of dopaminergic neurons in the substantia nigra. Immunhistochemical analysis of the substantia nigra of MCAO- and sham-treated TgM83 $3^{+/}$mice with an antibody against TH showed an ipsilateral loss of dopaminergic neurons 360 days after MCAO (a). Quantification of TH-positive cells revealed a significant loss of dopaminergic neurons on the ipsilateral side of the substantia nigra of $\mathrm{TgM} 83^{+/-}$ mice after MCAO-treatment (dark red) relative to the contralateral side (light red) or to sham-treated control animals (dark and light blue) at 360 days post surgery (b). The data represent the mean count of TH-positive cells per coronal section of the substantia nigra \pm standard deviation. Four coronal brain sections of three to five animals were analyzed per group 14,30,90, 180, and 360 days post surgery. $P$ values were computed using two-way ANOVA followed by Tukey's post-hoc test $\left(P:{ }^{* *}<0.01,{ }^{* * *}<0.001\right)$. The scale bar represents $0.5 \mathrm{~mm}$ revealed that a significant number of dopaminergic neurons was lost by 360 days post surgery in the ipsilateral brain hemisphere of mice that had been subjected to MCAO (Fig. 4b). In contrast, no significant loss of dopaminergic neurons was detected in the contralateral brain hemisphere of mice subjected to $\mathrm{MCAO}$, or in the brains of mice that had been subjected to sham surgery (Fig. 4b).

\section{Stroke induces aggregation of a-synuclein in the CNS of $\mathrm{TgM} 83^{+/-}$mice}

To assess if the loss of dopaminergic neurons in the substantia nigra could be due to an accumulation of toxic species of aggregated $\alpha$-synuclein, we first quantified the amount of human $\alpha$-synuclein protein in the brains of $\mathrm{TgM}_{83}{ }^{+-}$mice after stroke by ELISA (Fig. 5a). Following MCAO, we observed an initial apparent decline in $\alpha$-synuclein levels in both brain hemispheres of $\mathrm{TgM} 83^{+/-}$mice until 180 days post surgery, after which $\alpha$-synuclein levels slightly rose again but remained below those measured in animals at 360 days after sham surgery (Fig. 5a). Sham surgery did not cause significant changes in $\alpha$-synuclein protein levels at any time (Fig. 5a). Because oligomerization and aggregation of $\alpha$-synuclein after stroke could explain an apparent reduction in $\alpha$-synuclein protein levels, we next quantified the amount of aggregated $\alpha$-synuclein in the brains of $\mathrm{TgM} 83^{+/-}$mice after stroke by FRET analysis (Fig. 5b). Surprisingly, we measured continuously rising levels of oligomerized/aggregated $\alpha$-synuclein in both brain hemispheres between 14 and 360 days after stroke. In contrast, sham surgery did not induce detectable aggregation of $\alpha$-synuclein at any time (Fig. 5b).

\section{Brains of symptomatic $\mathrm{TgM}^{+/-}$mice reveal intracellular deposits of pathologic a-synuclein}

To further assess $\alpha$-synuclein aggregation in the CNS of $\mathrm{TgM} 83^{+/-}$mice after stroke, we stained coronal brain tissue sections of animals sacrificed at 360 days after MCAO or sham surgery by immunohistochemistry with three different antibodies, pSyn\#64 (Fig. 6a-g), EP1536Y (Fig. 6h, i), and 81A (Fig. 6j, k), recognizing phosphorylated serine at position 129 of $\alpha$-synuclein, which is associated with the cellular accumulation of pathologic $\alpha$-synuclein deposits (Fig. 6) [17, 22, 33]. All three antibodies detected cytosolic, perinuclear, and dendritic accumulation of pathologic $\alpha$-synuclein. Staining with the $81 \mathrm{~A}$ antibody resulted in more background than with the other two antibodies as it also cross reacts with phosphorylated neurofilament subunit L [44]. In contrast, animals that had undergone sham surgery did not exhibit deposits of pathologic $\alpha$-synuclein (Fig. $6 \mathrm{~g}$, $\mathrm{i}, \mathrm{k})$. We detected deposits of pathologic $\alpha$-synuclein in 


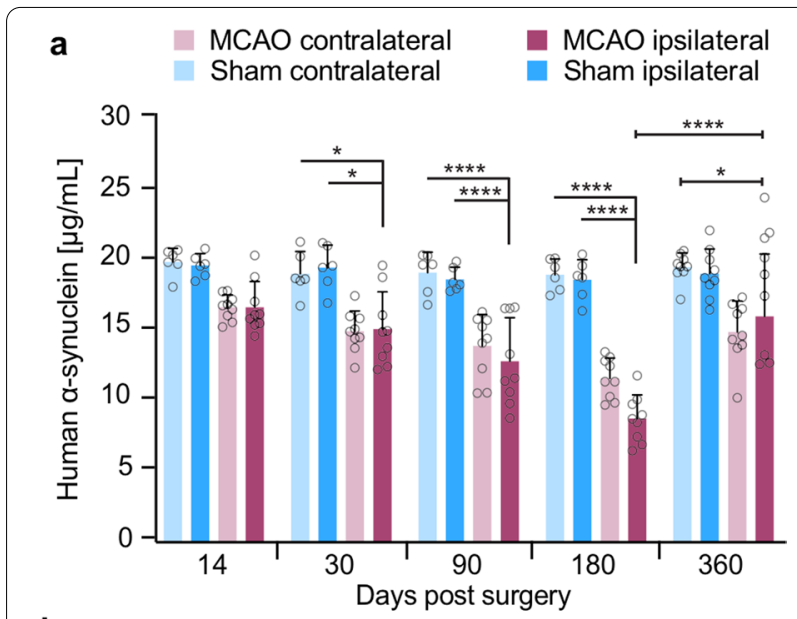

b

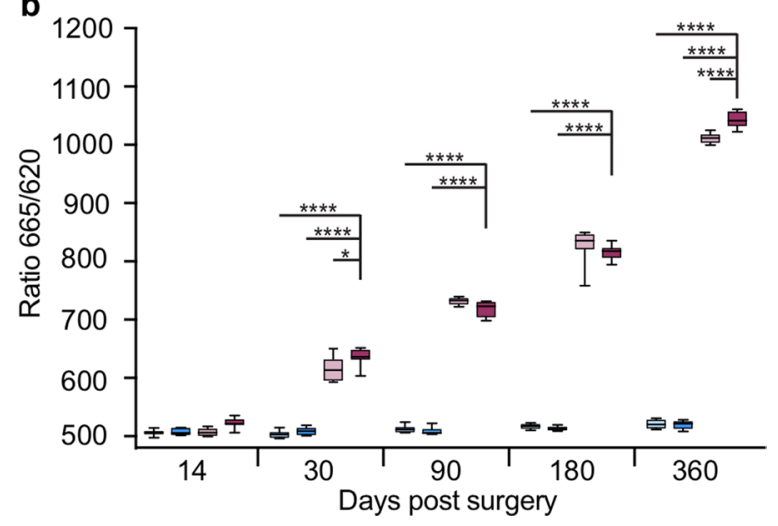

Fig. $5 \mathrm{MCAO}$ induces a continuous long-term increase of aggregated a-synuclein species in the CNS of $\mathrm{TgM} 83^{+/-}$mice. Quantification of the amount of human a-synuclein protein by ELISA in brain homogenates of TgM83 $3^{+/-}$mice subjected to MCAO showed a continuous decline in the ipsi- (dark red) and contralateral (light red) brain hemisphere up to 180 days post surgery, after which a-synuclein levels slightly rose again but did not reach levels detected in the brains of animals at 360 days post sham surgery (a). No changes in a-synuclein protein levels were observed in the ipsi- (dark blue) or contralateral (light blue) brain hemisphere of animals after sham surgery. Quantification of aggregated a-synuclein species by FRET analysis in brain homogenates of TgM83 ${ }^{+/-}$mice revealed a steady increase in the ipsi- (dark red) and contralateral (light red) brain hemisphere beginning 30 days post surgery (b). In contrast, a-synuclein did not aggregate in the brains of $\mathrm{TgM} 83^{+/-}$ mice after sham surgery. Both brain hemispheres of three animals each were analyzed per group at 14,30,90,180, and 360 days post surgery. The ELISA data represents the mean \pm standard deviation. The FRET data are shown as boxplots. $P$ values were computed using two-way ANOVA followed by Tukey's post-hoc test $\left(P:{ }^{*}<0.05\right.$, $* * * *<0.0001)$

various brain regions (Fig. 7a). A systematic quantification of brain pathology showed that deposits of phosphorylated $\alpha$-synuclein were rarely present in rostral or cortical brain regions (bregma $0.74 \mathrm{~mm}$ and $-1.70 \mathrm{~mm}$ ). In contrast, $25-100$ cells $/ \mathrm{mm}^{2}$ positive for phosphorylated $\alpha$-synuclein were detected in more caudal midbrain regions (bregma $-2.92 \mathrm{~mm}$ and $-4.84 \mathrm{~mm}$ ), and with a trend for increased deposition in the ipsilateral versus the contralateral hemisphere (Fig. 7b, Additional file 4). Most pathology was localized in the brain stem (bregma $-5.68 \mathrm{~mm}$ ) with up to 150 cells $/ \mathrm{mm}^{2}$ positive for phosphorylated $\alpha$-synuclein in both hemispheres (Fig. 7b, Additional file 4). Pathology was most pronounced 360 days post surgery but cellular deposits of pathologic $\alpha$-synuclein in some animals were also detectable already 180 days after stroke but not earlier (Additional file 5).

\section{Pathologic a-synuclein colocalizes with neurons, oligodendrocytes, and microglia in symptomatic $\mathrm{TgM}_{3} 3^{+/-}$ mice}

To identify which cell types accumulate pathologic $\alpha$-synuclein, we performed immunofluorescence staining of brain stem tissue sections of mice sacrificed 360 days after MCAO (Fig. 8). Co-staining for phosphorylated $\alpha$-synuclein and the neuronal marker NeuN revealed neuronal accumulation of pathologic $\alpha$-synuclein deposits. Co-staining with an antibody to oligodendrocyte transcription factor 2 (Olig2), a marker for oligodendrocytes, showed that also some oligodendrocytes harbored pathologic $\alpha$-synuclein. Positive co-staining for phosphorylated $\alpha$-synuclein and the microglial marker Ibal but not the astrocyte marker GFAP suggests that microglia but not astrocytes phagocytose pathologic $\alpha$-synuclein from the periphery. In agreement with our previous findings, no deposits of phosphorylated $\alpha$-synuclein were detected in any of these four cell types in brain stem tissue sections of mice sacrificed 360 days post sham surgery (Fig. 8).

\section{Discussion}

Little is known about $\alpha$-synuclein levels in the brains of patients after stroke. $\alpha$-Synuclein is naturally present in red blood cells and elevated levels of oligomeric, hemoglobin-bound, and phosphorylated $\alpha$-synuclein have been reported in red blood cells of ischemic stroke patients relative to healthy subjects $[5,58,60]$. Here we examined the pathologic effects of cerebral ischemia in $\mathrm{TgM} 83^{+/-}$ mice for up to a year after the initial insult (Fig. 9). To our knowledge this is the first study of its kind to investigate the effects of cerebral ischemia on $\alpha$-synuclein misfolding and its consequences in rodents for such a long duration $[25,53]$. Ischemic mice developed significant motor deficits beginning at 180 days post ischemia that worsened over time. Histological analysis revealed that these motor deficits were accompanied by a significant loss of dopaminergic neurons on the ipsilateral side of the substantia nigra, which became evident at 360 days post ischemia. Following MCAO, we also measured a steadily increasing amount of oligomerized/aggregated $\alpha$-synuclein in the 


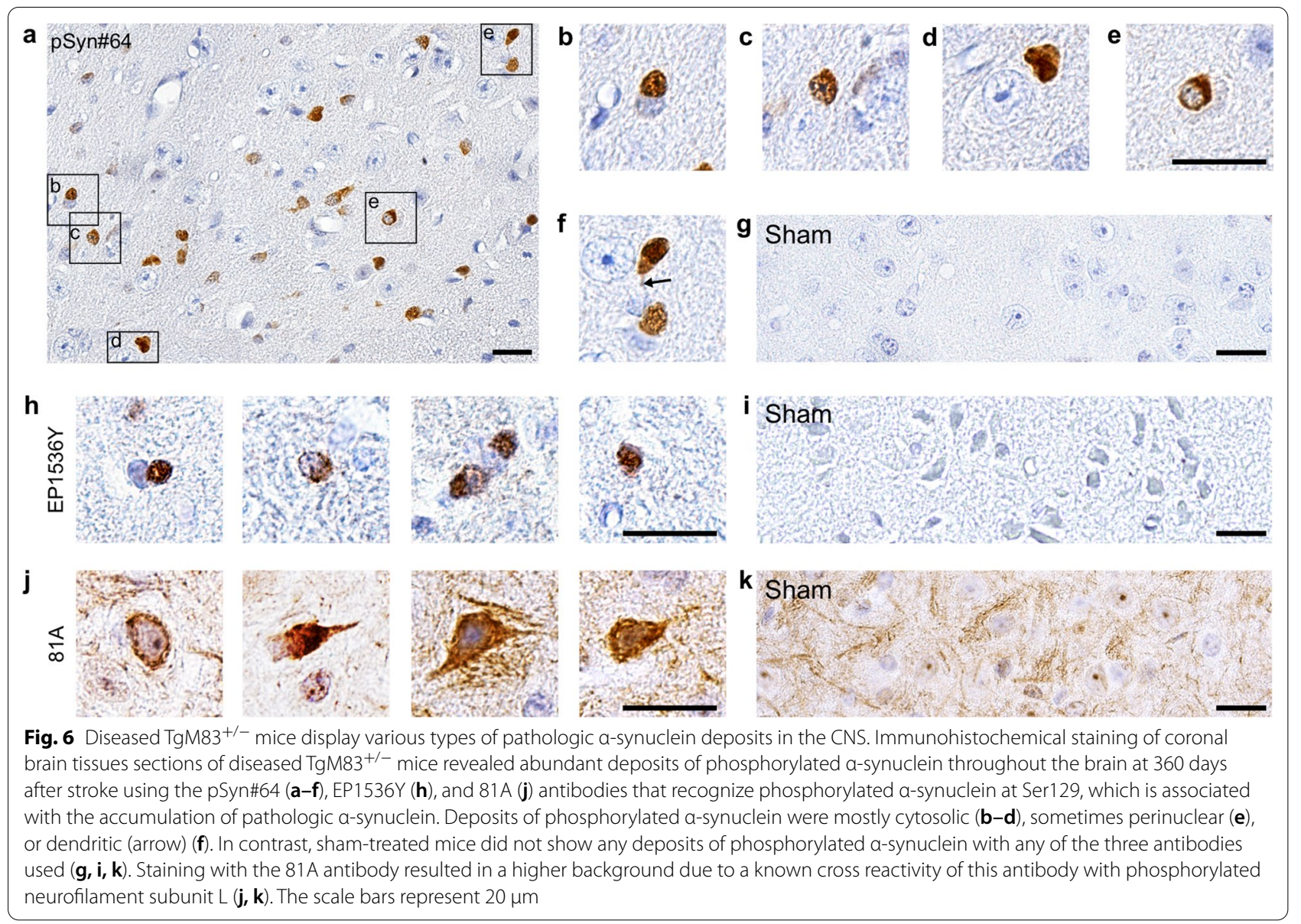

brains of ischemic animals, which resulted in neuronal deposits of pathologic $\alpha$-synuclein throughout the brain when the animals became symptomatic between 180 and 360 days after ischemia. We also observed a biphasic neuroinflammatory process with microgliosis and astrogliosis in the brains of ischemic animals that was stronger in the ipsilateral side but with time also increasingly present in the contralateral brain hemisphere. Neuroinflammation was first induced directly after MCAO due to the infarct and then gradually subsided. Ischemia and reperfusion are well known to induce an inflammatory response, which enhances clearing mechanisms such as protein degradation $[15,41]$. Normally, an inflammatory response eventually subsides, since a continued response would be detrimental to the surrounding tissue. To our surprise, after the initial inflammatory response had subsided a renewed response followed the first and manifested 180-360 days after ischemia. This concomitantly happened during a phase when cellular deposits of pathologic $\alpha$-synuclein and motor deficits first became detectable. This suggests that the secondary inflammation was in response to neuronal deposition of pathologic $\alpha$-synuclein and an associated cell loss, which we have previously observed in $\mathrm{TgM} 83^{+/-}$mice after challenge with synthetic $\alpha$-synuclein fibrils [10, 32]. Previous studies in wild-type and transgenic mice overexpressing human $\alpha$-synuclein with the familial A30P mutation subjected to a $30 \mathrm{~min}$ MCAO have reported $\alpha$-synuclein aggregation in ischemic neurons after $72 \mathrm{~h}$ of reperfusion [53]. Another study reported aggregation of $\alpha$-synuclein in ischemic neurons of wild-type mice after a 90 min MCAO with a reperfusion time of four months [25]. Importantly, neither of these studies investigated the long-term effects of stroke on $\alpha$-synuclein aggregation, the appearance of pathologic $\alpha$-synuclein in nonischemic brain regions, nor did they report any loss of dopaminergic neurons or subsequent motor disease in ischemic animals. Our results show that ischemic stroke can trigger $\alpha$-synuclein aggregation in the CNS and neurological disease in $\mathrm{TgM} 83^{+/-}$mice long before these animals naturally develop any neuropathology, providing a mechanistic link between cerebral ischemia and the elevated risk of PD. 


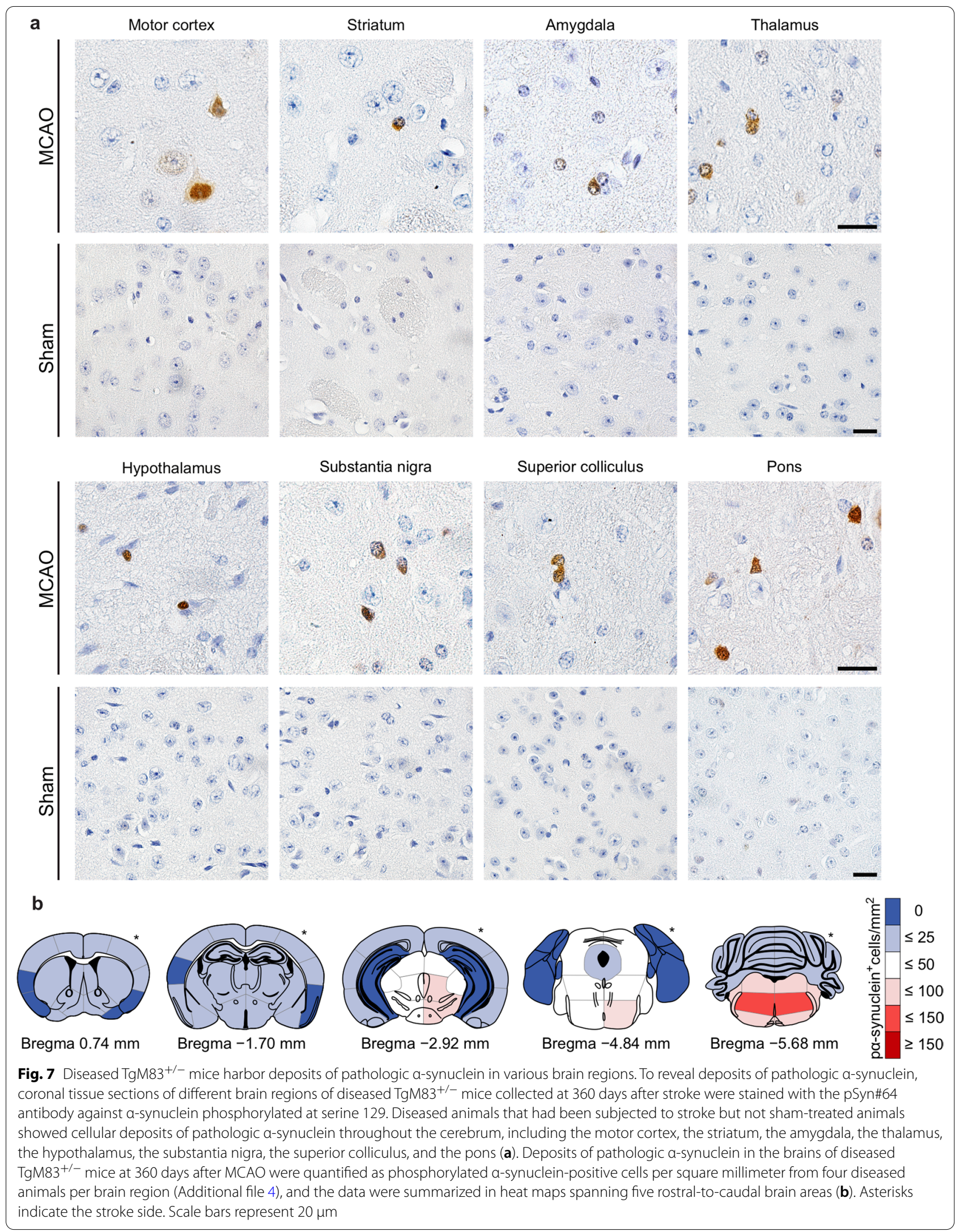


After ischemia, neurons of $\mathrm{TgM} 83^{+/-}$mice accumulated cytosolic, dendritic, and perinuclear deposits of pathologic $\alpha$-synuclein as has been reported for $\mathrm{TgM} 3^{+/-}$mice challenged with synthetic $\alpha$-synuclein fibrils or brain homogenates of patients with multiple system atrophy (MSA) [10, 29, 32, 57]. Interestingly, we also detected phosphorylated $\alpha$-synuclein in the nucleus of some neurons and oligodendrocytes after ischemia. Consistent with our findings, Kim and colleagues also reported a significant increase of phosphorylated $\alpha$-synuclein in the nucleus of neurons $24 \mathrm{~h}$ after ischemia [25]. Deposits of pathologic $\alpha$-synuclein in oligodendrocytes are characteristic for patients with MSA, where they are mostly localized to the cytosol [47]. Further research is necessary to see whether the ischemic microenvironment might lead to distinct $\alpha$-synuclein strains that can trigger different types of synucleinopathies [29, 40, 50].

While we find evidence for a pathological cascade that is set in motion after stroke causing $\alpha$-synuclein to aggregate and resulting in a loss of motor neurons and PD-like symptoms, this study has limitations. We do not know how stroke triggers $\alpha$-synuclein aggregation. Several possible explanations exist. During MCAO and the following reperfusion, immune cells are activated and recruited to the infarct region and release reactive oxygen species, which have been reported to enhance accumulation and spreading of pathologic $\alpha$-synuclein in the brain $[18,37]$. $\mathrm{N}$ - and $\mathrm{C}$-terminal oxidation of methionine residues in $\alpha$-synuclein by reactive oxygen species is thought to drive $\alpha$-synuclein oligomerization and inclusion body formation $[12,36]$. Also, oxidation of $\alpha$-synuclein may induce alterations in its structure that inhibit its degradation via the $20 \mathrm{~S}$ proteasome and thus favor its aggregation $[2,35]$. In the aftermath of ischemic stroke, we measured an increase in $\alpha$-synuclein oligomerization/aggregation in both brain hemispheres. In patients with PD, inflammation and microglial activation in graft deposits is observed long before the accumulation of $\alpha$-synuclein pathology in implanted dopamine neurons, suggesting that microglial activation contributes to the development of $\alpha$-synuclein pathology [39]. Our findings suggest that early ischemic events, possibly the spread of reactive oxygen species, may trigger oligomerization/aggregation of $\alpha$-synuclein in both brain hemispheres, and that a subsequent microglial activation contributes to the neuronal deposition of pathologic $\alpha$-synuclein. Pathologic $\alpha$-synuclein may also spread on its own accord to distal brain regions, including the contralateral brain hemisphere, or may be locally induced there to aggregate after the arrival of reactive oxygen species originating in the infarct region $[7,9,27,31,34]$. Another limitation is that we decided to terminate this study at 360 days after stroke, when the animals had already developed motor deficits but had not started to lose body weight or to show other overt disease symptoms such as kyphosis yet. Previous studies after challenge with $\alpha$-synuclein fibrils have shown that $\mathrm{TgM} 83^{+/-}$mice with terminal disease lose body weight and display more $\alpha$-synuclein pathology in their CNS than observed here at 360 days after stroke $[10,32]$. Another limitation of this study is the lack of wild-type controls. Here we used only $\mathrm{TgM} 83^{+/-}$mice to investigate the emergence and propagation of pathologic $\alpha$-synuclein after stroke. Future experiments with possibly longer occlusion times of the middle cerebral artery and/or longer incubation periods after stroke are necessary to conclude whether ischemic stroke can induce a synucleinopathy with clinical symptoms also in wild-type mice.

Few large-scale epidemiological studies have evaluated the association between prior stroke and PD [6, 28]. As a first, Becker and colleagues quantified the risk of a first-time diagnosis of idiopathic PD in patients with a history of stroke using the UK-based General Practice Research Database to compare the prevalence of stroke/TIA in 3637 newly diagnosed PD patients and in a matched comparison group without PD between 1994 and 2005 [6]. They concluded that a history of stroke was associated with a significantly increased relative risk of being diagnosed with PD compared to patients without such a history with an adjusted odds ratio of 1.65 and a $95 \%$ confidence interval of 1.47-2.00. More recently, Kummer and colleagues conducted a much larger retrospective cohort study using claims

(See figure on next page.)

Fig. 8 Pathologic a-synuclein colocalizes with neurons, oligodendrocytes, and microglia in the CNS of diseased TgM83 ${ }^{+/-}$mice.

Immunofluorescence staining of tissue sections of the brain stem show that phosphorylated a-synuclein (pSyn\#64, red) colocalizes with neurons (NeuN, green) as well as with oligodendrocytes (Olig2, green) in mice 360 days after MCAO as indicated by yellow arrows. Deposits of phosphorylated a-synuclein (pSyn\#64, red) were additionally seen to colocalize with microglia (Iba1, white) but not with astrocytes (GFAP, white) as indicated by yellow arrows. Neurons, oligodendrocytes, microglia, or astrocytes of mice that underwent sham-surgery, for which only merged images are shown, did not accumulate any phosphorylated a-synuclein deposits. Nuclear staining with DAPI is shown in blue. The scale bar represents $10 \mu \mathrm{m}$ 


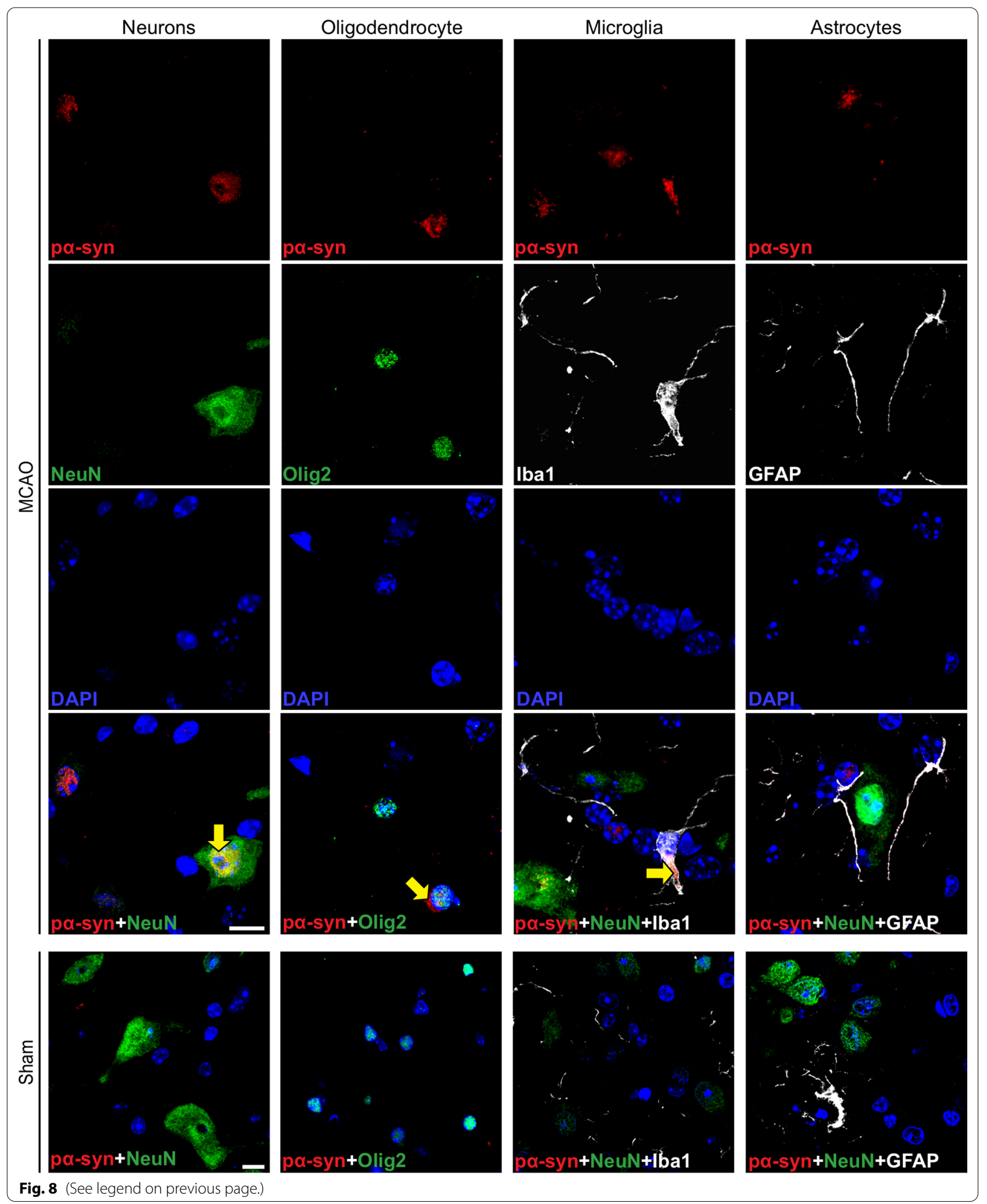




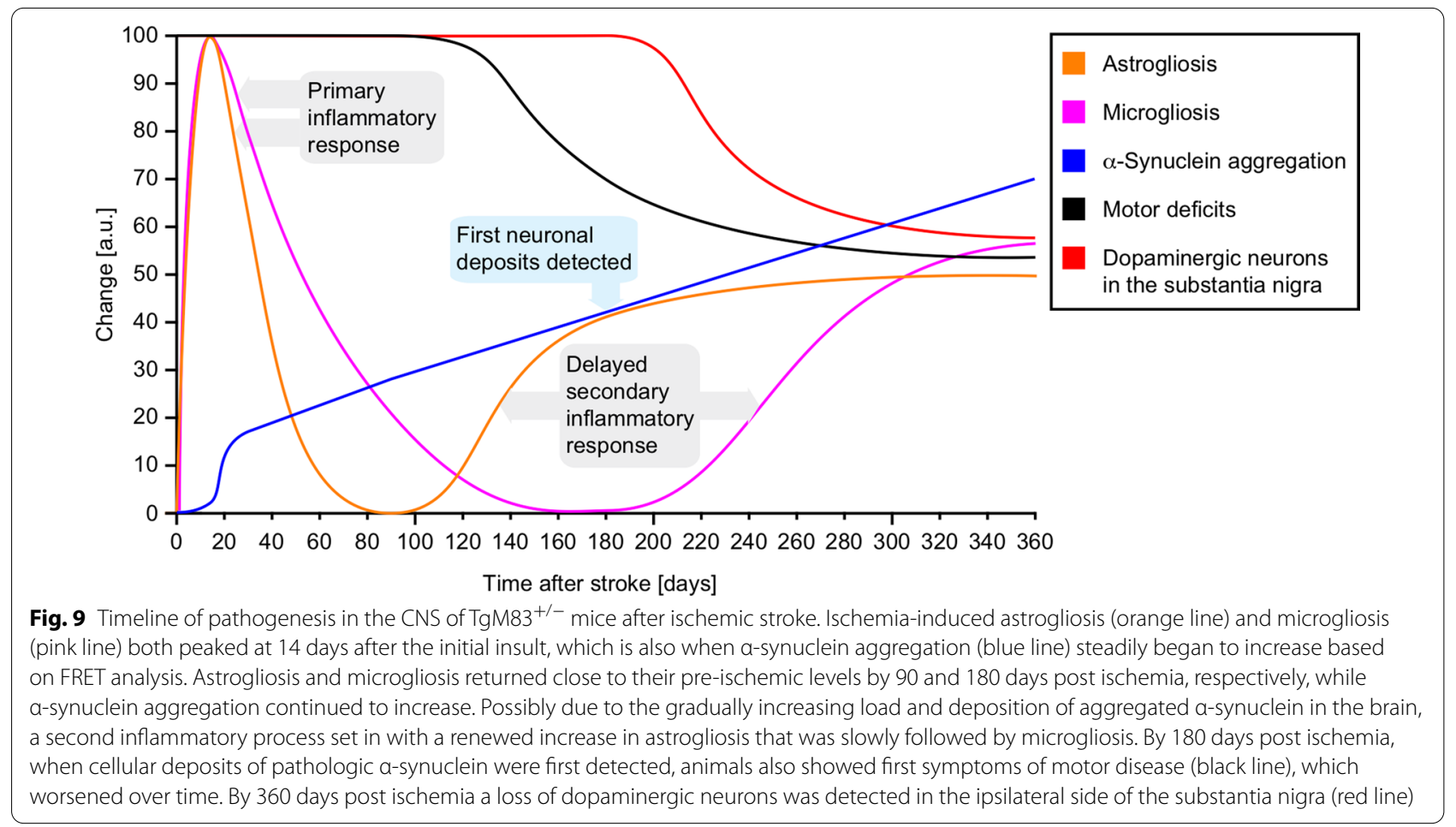

data from a $5 \%$ random sample of Medicare beneficiaries in the USA from 2008-2015 [28]. Among 1,035,536 Medicare beneficiaries followed for a mean of 5.2 years, 15,531 (1.5\%) participants were diagnosed with PD. In this study, stroke was one of the highest risk factors associated with a subsequent diagnosis of PD with a hazard ratio of 1.55 and a 95\% confidence interval of 1.39-1.72. Both studies conclude that ischemic stroke increases the risk of developing PD. More importantly, because these studies do not evaluate the risk of PD after silent stroke, which affect up to $28 \%$ of the population, theses studies likely underestimate the risk of PD after stroke $[54,55]$.

To date no mechanistic insights or animal models exist that sufficiently explain this causal relationship or could be used to study it. Here, we have established a new mouse model to investigate this problem: MCAO in $\mathrm{TgM}_{83}{ }^{+/-}$mice in combination with a one-year follow up revealed a causal link between mild cerebral ischemia and PD. Cerebral ischemia resulted in aggregation of $\alpha$-synuclein and a concomitant loss of dopaminergic neurons in the substantia nigra, which subsequently resulted in PD-like symptoms. Mice displayed significant motor deficits within a year after MCAO. Neuroinflammation was first significantly induced at an early time point due to the infarct and then quickly subsided and, surprisingly, resurfaced again after 6-12 months. This late-stage neuroinflammatory response coincided with a significantly increased deposition of pathologic $\alpha$-synuclein throughout the brain. Our findings provide a possible explanation of how cerebral ischemia can lead to PD and an animal model to further study this relationship and potential therapeutic interventions.

\section{Supplementary Information}

The online version contains supplementary material available at https://doi. org/10.1186/s40478-022-01327-6.

Additional file 1: Table S1. Antibodies used for immunofluorescence and immunohistochemistry.

Additional file 2. $\operatorname{TgM} 3^{+/-}$mice do not show any neuronal loss following sham surgery Immunohistochemical staining for NeuN showed that sham surgery did not cause any neuronal loss in the ipsilateral or contralateral brain hemispheres of $\mathrm{TgM}^{+/-} 3^{+-}$mice at 14 (a), 30 (b), 90 (b), 180 (b), or 360 days (b) after sham surgery. The scale bar represents $0.5 \mathrm{~mm}$.

Additional file 3. Spread of neuroinflammation to the contralateral brain hemisphere by 360 days after stroke. Staining of brain tissue sections of MCAO- and sham-treated TgM83 ${ }^{+/-}$mice with antibodies to lba1 (a) and to GFAP $(\mathbf{b})$ revealed that microgliosis and astrogliosis had spread to the contralateral brain hemisphere by 360 days after stroke. A higher amount of microglia was found throughout the entire contralateral brain hemisphere of MCAO-treated animals compared to sham-treated animals (a). Also, a higher amount of astrocytes was detected in the contralateral brain hemisphere of MCAO-treated animals compared to sham-treated animals, especially in the lower isocortical region and the upper part of the caudoputamen (b). Scale bars represent $1.0 \mathrm{~mm}$.

Additional file 4. Quantification of phosphorylated a-synuclein deposits in different brain regions of $\mathrm{TgM} 83^{+/-}$at 360 days after stroke. The number of phosphorylated a-synuclein-positive cells per square millimeter was plotted for the ipsilateral and contralateral brain hemisphere for 
each quantified brain area of mice subjected to stroke. The coordinates of the quantified coronal tissue sections relative to the bregma were 0.74 $\mathrm{mm}(\mathbf{a}),-1.70 \mathrm{~mm}(\mathbf{b}),-2.92 \mathrm{~mm}(\mathbf{c}),-4.84 \mathrm{~mm}(\mathbf{d})$, and $-5.68 \mathrm{~mm}(\mathbf{e})$ as shown in the heat map in Fig. 7b. Data shown represent the mean \pm standard deviation of four animals.

Additional file 5. $\mathrm{TgM} 83^{+/-}$mice harbor deposits of pathologic a-synuclein throughout the brain at 180 days after stroke. Immunohistochemical staining of coronal brain tissue sections with the pSyn\#64 antibody against a-synuclein phosphorylated at serine 129 revealed deposits throughout the brain of diseased animals at 180 days after MCAO. Deposits were present throughout the cerebrum, including the thalamus, hypothalamus, substantia nigra, and superior colliculus. In contrast, none of the animals that underwent sham surgery displayed any deposits of phosphorylated a-synuclein, even at 360 days after surgery. The scale bar represents $10 \mu \mathrm{m}$.

\section{Acknowledgements}

We thank Luis Mario Aguirre-Palma, Rachana Subedi, Olga Sharma, and Lioba Zohren for excellent technical assistance, the staff of the DZNE microscopy and animal facilities, and the staff of the Forschungszentrum Jülich animal facility for technical support. We thank Ina Vorberg for hosting SL.

\section{Authors' contributions}

GT conceived and designed the study. SL, JG, MEB, VP, LM, and SR contributed to data acquisition. SL and JG contributed to statistical analysis. SL, JG, and GT contributed to data interpretation and writing. All authors read and approved the final manuscript.

\section{Funding}

This study was funded by the German Research Center for Neurodegenerative Diseases (DZNE) and the Forschungszentrum Jülich GmbH.

\section{Availability of data and materials}

All data generated or analyzed during this study are included in this published article [and its supplementary information files].

\section{Declarations}

\section{Ethics approval and consent to participate}

All studies involving animals were approved by the animal protection committee of the North Rhine-Westphalia State Environment Agency (LANUV). All applicable international, national, and/or institutional guidelines for the care and use of animals were followed. This article does not contain any studies with human participants performed by any of the authors.

\section{Competing interests}

The authors declare that they have no competing interests.

\section{Author details}

${ }^{1}$ German Center for Neurodegenerative Diseases (DZNE), Venusberg-Campus 1, Gebäude 99, 53127 Bonn, Germany. ${ }^{2}$ Institut für Biologische Informationsprozesse, Strukturbiochemie (IBI-7), Forschungszentrum Jülich $\mathrm{GmbH}$, Wilhelm-Johnen-Straße, 52425 Jülich, Germany. Institut für Physikalische Biologie, Heinrich-Heine-Universität Düsseldorf, Universitätsstraße 1, 40225 Düsseldorf, Germany.

Received: 14 December 2021 Accepted: 1 February 2022 Published online: 24 February 2022

\section{References}

1. Dement A (2020) Alzheimer's disease facts and figures. Alzheimer's Dementia 16:391-460. https://doi.org/10.1002/alz.12068

2. Alvarez-Castelao B, Goethals M, Vandekerckhove J, Castano JG (2014) Mechanism of cleavage of alpha-synuclein by the $20 \mathrm{~S}$ proteasome and modulation of its degradation by the RedOx state of the $\mathrm{N}$-terminal methionines. Biochem Biophys Acta 1843:352-365. https://doi.org/10. 1016/j.bbamcr.2013.11.018

3. Ascherio A, Schwarzschild MA (2016) The epidemiology of Parkinson's disease: risk factors and prevention. Lancet Neurol 15:1257-1272. https:// doi.org/10.1016/S1474-4422(16)30230-7

4. Baba M, Nakajo S, Tu PH, Tomita T, Nakaya K, Lee VM, Trojanowski JQ, Iwatsubo T (1998) Aggregation of alpha-synuclein in Lewy bodies of sporadic Parkinson's disease and dementia with Lewy bodies. Am J Pathol 152:879-884

5. Barbour R, Kling K, Anderson JP, Banducci K, Cole T, Diep L, Fox M, Goldstein JM, Soriano F, Seubert P et al (2008) Red blood cells are the major source of alpha-synuclein in blood. Neurodegener Dis 5:55-59. https:// doi.org/10.1159/000112832

6. Becker C, Jick SS, Meier CR (2010) Risk of stroke in patients with idiopathic Parkinson disease. Parkinsonism Relat Disord 16:31-35. https://doi.org/10. 1016/j.parkreldis.2009.06.005

7. Bernis ME, Babila JT, Breid S, Wüsten KA, Wüllner U, Tamgüney G (2015) Prion-like propagation of human brain-derived alpha-synuclein in transgenic mice expressing human wild-type alpha-synuclein. Acta Neuropathol Commun 3:75. https://doi.org/10.1186/s40478-015-0254-7

8. Block F, Dihne M, Loos M (2005) Inflammation in areas of remote changes following focal brain lesion. Prog Neurobiol 75:342-365. https://doi.org/ 10.1016/j.pneurobio.2005.03.004

9. Braak H, Del Tredici K, Rub U, de Vos RA, Jansen Steur EN, Braak E (2003) Staging of brain pathology related to sporadic Parkinson's disease. Neurobiol Aging 24:197-211. https://doi.org/10.1016/S0197-4580(02)00065-9

10. Breid S, Bernis ME, Babila JT, Garza MC, Wille H, Tamgüney G (2016) Neuroinvasion of alpha-Synuclein Prionoids after intraperitoneal and intraglossal inoculation. JVirol 90:9182-9193. https://doi.org/10.1128/JVI. 01399-16

11. Burre J, Sharma M, Tsetsenis T, Buchman V, Etherton MR, Südhof TC (2010) Alpha-synuclein promotes SNARE-complex assembly in vivo and in vitro. Science 329:1663-1667. https://doi.org/10.1126/science.1195227

12. Carmo-Goncalves P, Pinheiro AS, Romao L, Cortines J, Follmer C (2014) UV-induced selective oxidation of Met5 to Met-sulfoxide leads to the formation of neurotoxic fibril-incompetent alpha-synuclein oligomers. Amyloid 21:163-174. https://doi.org/10.3109/13506129.2014.912208

13. Chouchani ET, Pell VR, Gaude E, Aksentijevic D, Sundier SY, Robb EL, Logan A, Nadtochiy SM, Ord ENJ, Smith AC et al (2014) Ischaemic accumulation of succinate controls reperfusion injury through mitochondrial ROS. Nature 515:431-435. https://doi.org/10.1038/nature13909

14. Collaborators GBDCoD (2018) Global, regional, and national age-sexspecific mortality for 282 causes of death in 195 countries and territories, 1980-2017: a systematic analysis for the Global Burden of Disease Study 2017. Lancet 392: 1736-1788. https://doi.org/10.1016/S0140-6736(18) 32203-7

15. Eltzschig HK, Eckle T (2011) Ischemia and reperfusion — from mechanism to translation. Nat Med 17:1391-1401. https://doi.org/10.1038/nm.2507

16. Franklin KBJ, Paxinos G (2007) The mouse brain in stereotaxic coordinates. Academic Press, Amsterdam

17. Fujiwara H, Hasegawa M, Dohmae N, Kawashima A, Masliah E, Goldberg MS, Shen J, Takio K, Iwatsubo T (2002) Alpha-synuclein is phosphorylated in synucleinopathy lesions. Nat Cell Biol 4:160-164. https://doi.org/10. $1038 /$ ncb748

18. Gao HM, Kotzbauer PT, Uryu K, Leight S, Trojanowski JQ, Lee VM (2008) Neuroinflammation and oxidation/nitration of alpha-synuclein linked to dopaminergic neurodegeneration. J Neurosci 28:7687-7698. https://doi. org/10.1523/JNEUROSCI.0143-07.2008

19. Giasson BI, Duda JE, Quinn SM, Zhang B, Trojanowski JQ, Lee VM (2002) Neuronal alpha-synucleinopathy with severe movement disorder in mice expressing A53T human alpha-synuclein. Neuron 34:521-533. https://doi. org/10.1016/S0896-6273(02)00682-7

20. Howard VJ, McClure LA, Meschia JF, Pulley L, Orr SC, Friday GH (2006) High prevalence of stroke symptoms among persons without a diagnosis of stroke or transient ischemic attack in a general population: the REasons for geographic and racial differences in Stroke (REGARDS) study. Arch Intern Med 166:1952-1958. https://doi.org/10.1001/archinte.166.18.1952

21. ladecola C, Zhang F, Casey R, Nagayama M, Ross ME (1997) Delayed reduction of ischemic brain injury and neurological deficits in mice lacking the inducible nitric oxide synthase gene. J Neurosci 17:9157-9164 
22. Kahle PJ, Neumann M, Ozmen L, Muller V, Jacobsen H, Spooren W, Fuss B, Mallon B, Macklin WB, Fujiwara H et al (2002) Hyperphosphorylation and insolubility of alpha-synuclein in transgenic mouse oligodendrocytes. EMBO Rep 3:583-588. https://doi.org/10.1093/embo-reports/kvf109

23. Kalia LV, Lang AE (2015) Parkinson's disease. Lancet 386:896-912. https:// doi.org/10.1016/S0140-6736(14)61393-3

24. Kathner-Schaffert C, Karapetow L, Gunther M, Rudolph M, Dahab M, Baum E, Lehmann T, Witte OW, Redecker C, Schmeer CW et al (2019) Early stroke induces long-term impairment of adult neurogenesis accompanied by hippocampal-mediated cognitive decline. Cells. https://doi.org/10.3390/ cells8121654

25. Kim T, Mehta SL, Kaimal B, Lyons K, Dempsey RJ, Vemuganti R (2016) Poststroke induction of alpha-synuclein mediates ischemic brain damage. J Neurosci 36:7055-7065. https://doi.org/10.1523/JNEUROSCI.1241-16.2016

26. Klemann CJHM, Xicoy H, Poelmans G, Bloem BR, Martens Jasper GJM, Visser E (2018) Physical exercise modulates L-DOPA-regulated molecular pathways in the MPTP mouse model of Parkinson's disease. Mol Neurobiol 55(7):5639-5657. https://doi.org/10.1007/s12035-017-0775-0

27. Kordower JH, Chu Y, Hauser RA, Freeman TB, Olanow CW (2008) Lewy body-like pathology in long-term embryonic nigral transplants in Parkinson's disease. Nat Med 14:504-506. https://doi.org/10.1038/nm1747

28. Kummer BR, Diaz I, Wu X, Aaroe AE, Chen ML, ladecola C, Kamel H, Navi BB (2019) Associations between cerebrovascular risk factors and parkinson disease. Ann Neurol 86:572-581. https://doi.org/10.1002/ana.25564

29. Lau A, So RWL, Lau HHC, Sang JC, Ruiz-Riquelme A, Fleck SC, Stuart E, Menon S, Visanji NP, Meisl G et al (2019) Alpha-synuclein strains target distinct brain regions and cell types. Nat Neurosci. https://doi.org/10.1038/ s41593-019-0541-x

30. Levine DA, Galecki AT, Langa KM, Unverzagt FW, Kabeto MU, Giordani B, Wadley VG (2015) Trajectory of cognitive decline after incident stroke. JAMA 314:41-51. https://doi.org/10.1001/jama.2015.6968

31. Li JY, Englund E, Holton JL, Soulet D, Hagell P, Lees AJ, Lashley T, Quinn NP, Rehncrona S, Bjorklund A et al (2008) Lewy bodies in grafted neurons in subjects with Parkinson's disease suggest host-to-graft disease propagation. Nat Med 14:501-503. https://doi.org/10.1038/nm1746

32. Lohmann S, Bernis ME, Tachu BJ, Ziemski A, Grigoletto J, Tamgüney G (2019) Oral and intravenous transmission of alpha-synuclein fibrils to mice. Acta Neuropathol 138:515-533. https://doi.org/10.1007/s00401-019-02037-5

33. Lue LF, Walker DG, Adler CH, Shill H, Tran H, Akiyama H, Sue LI, Caviness J, Sabbagh MN, Beach TG (2012) Biochemical increase in phosphorylated alpha-synuclein precedes histopathology of Lewy-type synucleinopathies. Brain Pathol 22:745-756. https://doi.org/10.1111/j.1750-3639.2012.00585.x

34. Luk KC, Kehm V, Carroll J, Zhang B, O'Brien P, Trojanowski JQ, Lee VM (2012) Pathological al pha-synuclein transmission initiates Parkinson-like neurodegeneration in nontransgenic mice. Science 338:949-953. https://doi.org/ 10.1126/science. 1227157

35. Maltsev AS, Chen J, Levine RL, Bax A (2013) Site-specific interaction between alpha-synuclein and membranes probed by NMR-observed methionine oxidation rates. J Am Chem Soc 135:2943-2946. https://doi. org/10.1021/ja312415q

36. Mirzaei H, Schieler JL, Rochet JC, Regnier F (2006) Identification of rotenone-induced modifications in alpha-synuclein using affinity pull-down and tandem mass spectrometry. Anal Chem 78:2422-2431. https://doi.org/ 10.1021/ac051978n

37. Musgrove RE, Helwig M, Bae EJ, Aboutalebi H, Lee SJ, Ulusoy A, Di Monte DA (2019) Oxidative stress in vagal neurons promotes parkinsonian pathology and intercellular alpha-synuclein transfer. J Clin Invest 129:3738-3753. https://doi.org/10.1172/JC1127330

38. Nalls MA, Blauwendraat C, Vallerga CL, Heilbron $K$, Bandres-Ciga S, Chang D, Tan M, Kia DA, Noyce AJ, Xue A et al (2019) Identification of novel risk loci, causal insights, and heritable risk for Parkinson's disease: a meta-analysis of genome-wide association studies. Lancet Neurol 18:1091-1102. https://doi. org/10.1016/S1474-4422(19)30320-5

39. Olanow CW, Savolainen M, Chu Y, Halliday GM, Kordower JH (2019) Temporal evolution of microglia and alpha-synuclein accumulation following foetal grafting in Parkinson's disease. Brain 142:1690-1700. https://doi.org/ 10.1093/brain/awz104

40. Peelaerts W, Bousset L, Van der Perren A, Moskalyuk A, Pulizzi R, Giugliano M, Van den Haute C, Melki R, Baekelandt V (2015) Alpha-synuclein strains cause distinct synucleinopathies after local and systemic administration. Nature 522:340-344. https://doi.org/10.1038/nature14547
41. Pluta R, Januszewski S, Czuczwar SJ (2021) Neuroinflammation in postischemic neurodegeneration of the brain: friend, foe, or both? Int J Mol Sci. https://doi.org/10.3390/ijms22094405

42. Ray S, Singh N, Kumar R, Patel K, Pandey S, Datta D, Mahato J, Panigrahi R, Navalkar A, Mehra S et al (2020) Alpha-synuclein aggregation nucleates through liquid-liquid phase separation. Nat Chem 12:705-716. https:// doi.org/10.1038/s41557-020-0465-9

43. Rewell SS, Churilov L, Sidon TK, Aleksoska E, Cox SF, Macleod MR, Howells DW (2017) Evolution of ischemic damage and behavioural deficit over 6 months after MCAo in the rat: selecting the optimal outcomes and statistical power for multi-centre preclinical trials. PLOS ONE 12:e0171688. https://doi.org/10.1371/journal.pone.0171688

44. Sacino AN, Brooks M, Thomas MA, McKinney AB, McGarvey NH, Rutherford NJ, Ceballos-Diaz C, Robertson J, Golde TE, Giasson BI (2014) Amyloidogenic alpha-synuclein seeds do not invariably induce rapid, widespread pathology in mice. Acta Neuropathol 127:645-665. https:// doi.org/10.1007/s00401-014-1268-0

45. Schnell SA, Staines WA, Wessendorf MW (1999) Reduction of lipofuscinlike autofluorescence in fluorescently labeled tissue. J Histochem Cytochem 47:719-730. https://doi.org/10.1177/002215549904700601

46. Schweighauser M, Shi Y, Tarutani A, Kametani F, Murzin AG, Ghetti B, Matsubara T, Tomita T, Ando T, Hasegawa K et al (2020) Structures of alphasynuclein filaments from multiple system atrophy. Nature 585:464-469. https://doi.org/10.1038/s41586-020-2317-6

47. Spillantini MG, Crowther RA, Jakes R, Cairns NJ, Lantos PL, Goedert M (1998) Filamentous alpha-synuclein inclusions link multiple system atrophy with Parkinson's disease and dementia with Lewy bodies. Neurosci Lett 251:205-208. https://doi.org/10.1016/S0304-3940(98)00504-7

48. Spillantini MG, Crowther RA, Jakes R, Hasegawa M, Goedert M (1998) alpha-Synuclein in filamentous inclusions of Lewy bodies from Parkinson's disease and dementia with Lewy bodies. Proc Natl Acad Sci U S A 95:6469-6473. https://doi.org/10.1073/pnas.95.11.6469

49. Spillantini MG, Schmidt ML, Lee VM, Trojanowski JQ, Jakes R, Goedert M (1997) Alpha-synuclein in Lewy bodies. Nature 388:839-840. https://doi. org/10.1038/42166

50. Suzuki G, Imura S, Hosokawa M, Katsumata R, Nonaka T, Hisanaga SI, Saeki Y, Hasegawa M (2020) Alpha-synuclein strains that cause distinct pathologies differentially inhibit proteasome. Elife. https://doi.org/10.7554/eLife. 56825

51. Swanson RA, Morton MT, Tsao-Wu G, Savalos RA, Davidson C, Sharp FR (1990) A semiautomated method for measuring brain infarct volume. J Cereb Blood Flow Metab 10:290-293. https://doi.org/10.1038/jcbfm. 1990.47

52. Tamgüney $G$, Korczyn AD (2017) A critical review of the prion hypothesis of human synucleinopathies. Cell Tissue Res 373:213-220. https://doi.org/ 10.1007/s00441-017-2712-y

53. Unal-Cevik I, Gursoy-Ozdemir Y, Yemisci M, Lule S, Gurer G, Can A, Muller V, Kahle PJ, Dalkara T (2011) Alpha-synuclein aggregation induced by brief ischemia negatively impacts neuronal survival in vivo: a study in [A30P]alpha-synuclein transgenic mouse. J Cereb Blood Flow Metab 31:913-923. https://doi.org/10.1038/jcbfm.2010.170

54. Vermeer SE, Longstreth WT Jr, Koudstaal PJ (2007) Silent brain infarcts: a systematic review. Lancet Neurol 6:611-619. https://doi.org/10.1016/ S1474-4422(07)70170-9

55. Vermeer SE, Prins ND, den Heijer T, Hofman A, Koudstaal PJ, Breteler MM (2003) Silent brain infarcts and the risk of dementia and cognitive decline. N Engl J Med 348:1215-1222. https://doi.org/10.1056/NEJMoa022066

56. Virani SS, Alonso A, Aparicio HJ, Benjamin EJ, Bittencourt MS, Callaway CW, Carson AP, Chamberlain AM, Cheng S, Delling FN et al (2021) Heart disease and stroke statistics-2021 update: a report from the American Heart Association. Circulation 143:e254-e743. https://doi.org/10.1161/ CIR.0000000000000950

57. Watts JC, Giles K, Oehler A, Middleton L, Dexter DT, Gentleman SM, DeArmond SJ, Prusiner SB (2013) Transmission of multiple system atrophy prions to transgenic mice. Proc Natl Acad Sci U S A 110:19555-19560. https://doi.org/10.1073/pnas.1318268110

58. Wu Z, Li X, Zeng M, Qiu H, Feng H, Xu X, Yu S, Wu J (2019) Alpha-synuclein alterations in red blood cells of peripheral blood after acute ischemic stroke. Int J Clin Exp Pathol 12:1757-1763

59. Zhang J, Zhang Y, Xing S, Liang Z, Zeng J (2012) Secondary neurodegeneration in remote regions after focal cerebral infarction: a new target 
for stroke management? Stroke 43:1700-1705. https://doi.org/10.1161/ STROKEAHA. 111.632448

60. Zhao HQ, Li FF, Wang Z, Wang XM, Feng T (2016) A comparative study of the amount of alpha-synuclein in ischemic stroke and Parkinson's disease. Neurol Sci 37:749-754. https://doi.org/10.1007/s10072-016-2485-1

\section{Publisher's Note}

Springer Nature remains neutral with regard to jurisdictional claims in published maps and institutional affiliations.

- fast, convenient online submission

- thorough peer review by experienced researchers in your field

- rapid publication on acceptance

- support for research data, including large and complex data types

- gold Open Access which fosters wider collaboration and increased citations

- maximum visibility for your research: over $100 \mathrm{M}$ website views per year

At BMC, research is always in progress.

Learn more biomedcentral.com/submissions 